\title{
The Quality of Evidence in Knowledge Management Research: Practitioner versus Scholarly Literature
}

\author{
Hamid R. Ekbia; Noriko Hara
}

School of Library and Information Science, Indiana University

Correspondence to: Hamid Ekbia, 1320 E. 10 ${ }^{\text {th }}$ St. Bloomington, IN.47405-3907, Email: hekbia@indiana.edu

\section{Abstract}

The fragmentation of knowledge management as a field and as an area of research poses serious theoretical challenges for researchers. The viability of $\mathrm{KM}$ rests on how the community responds to these challenges, but it also depends on how they garner empirical support for their purported theories. One aspect of this would involve the evaluation of the evidence provided in KM research. This paper presents a comparative study of the evidence that is presented in scholarly and professional literature on KM. For this purpose, the paper introduces a typology of evidence to analyze the data obtained from the survey of the literature. The classification based on this typology reveals no systematic difference between the types of evidence put forth in the scholarly and practitioner literature. However, closer examination reveals interesting differences in terms of the questions they ask, the perspective they adopt, and the methods they follow to convince others of the validity their claims. We explain these differences in terms of the notions of "blackboxing" and "performance” borrowed from actor-network theory. Drawing upon lessons from the philosophy of science and science studies, we explicate the different degrees of blackboxing by professionals and scholars in translating data of studied cases into "evidence" that is then handed down to others who take interest in it. The implications of these differences for scholarly research on KM will be discussed.

Keywords: knowledge management, evidence, actor-network theory, social informatics 


\section{Introduction}

During the last decade, knowledge management (KM) has been promoted by professionals and scholars alike as a new reform in organization management. Management literature promote KM as a novel and strong managerial tool (e.g., [1]); organization literature advance it as an effective means for implementing organizational learning, for furthering innovation, and for guaranteeing continuity; and business literature portray it as a productivityenhancing tool. All of these accounts, furthermore, often establish a close link between knowledge management and information and communication technologies, presenting $\mathrm{KM}$ as the latest stage in the evolution of computerization in organizations (the previous stages being "data processing," "information systems," and so on).

Historically, scholarly research in management science seems to manifest the familiar pattern of a cyclical model of progress, where a new concept that emerges with excitement is often followed by critique and then transformation or decline in a matter of a few years [2]. KM research has certainly enjoyed an unusually long phase of popularity but as Gray and Meister [3] have argued, going through a similar cycle, it faces a serious theoretical challenge. The development of the field depends on how the community of KM scholars responds to this challenge. As a possible remedy, these authors propose the creation of integrative core theories of learning and knowledge-related phenomena in organizations. In our opinion, a key component of this remedy would be the formation of commonly acceptable criteria for the assessment of evidence in KM research. And one way to foster this, we suggest, is for the scholarly literature to pay closer attention to the "mundane" aspects of KM that is, to those aspects that relate to the local interactions of individuals within a physical and social environment [4].

These mundane aspects of KM are usually neglected in the professional accounts of KM, which are typically based on a managerialist framework. Outstanding, and probably most influential among professional accounts, are a number of popular books that constitute a body of literature widely read and cited by consultants, managers, and information officers in the business world. An analysis of this literature reveals a pattern of growing popularity during the first years of the introduction of $\mathrm{KM}$, followed by a decline in interest (see Figure 1), similar to what others have reported [5] although Guo and Sheffield [6] informed that annual output of scholarly articles on KM has been increasing up to 2004. One of the common features of these books is their emphasis on the increasing role of knowledge (and, hence, of knowledge management tools) in the new economy. In particular, they emphasize the importance of human experience, insight, and action as major components of knowledge. This human-centric view of KM is meant to balance and correct the techno-centric view that dominated previous computerization movements such as data processing and information systems. To support their view, these books usually draw upon a number of famous case studies of multinational companies, often relying on "evidence" such as anecdotes, market share statistics, financial reports, ... or a combination of these. As we shall see, this evidence is usually comes from managerial and "official" reports, and rarely involve any 


\section{The Quality of Evidence in Knowledge Management Research}

description of the "mundane" aspects of KM. Since the purpose of the case studies is typically to demonstrate the effective use of KM by these companies, they adopt a managerial perspective.

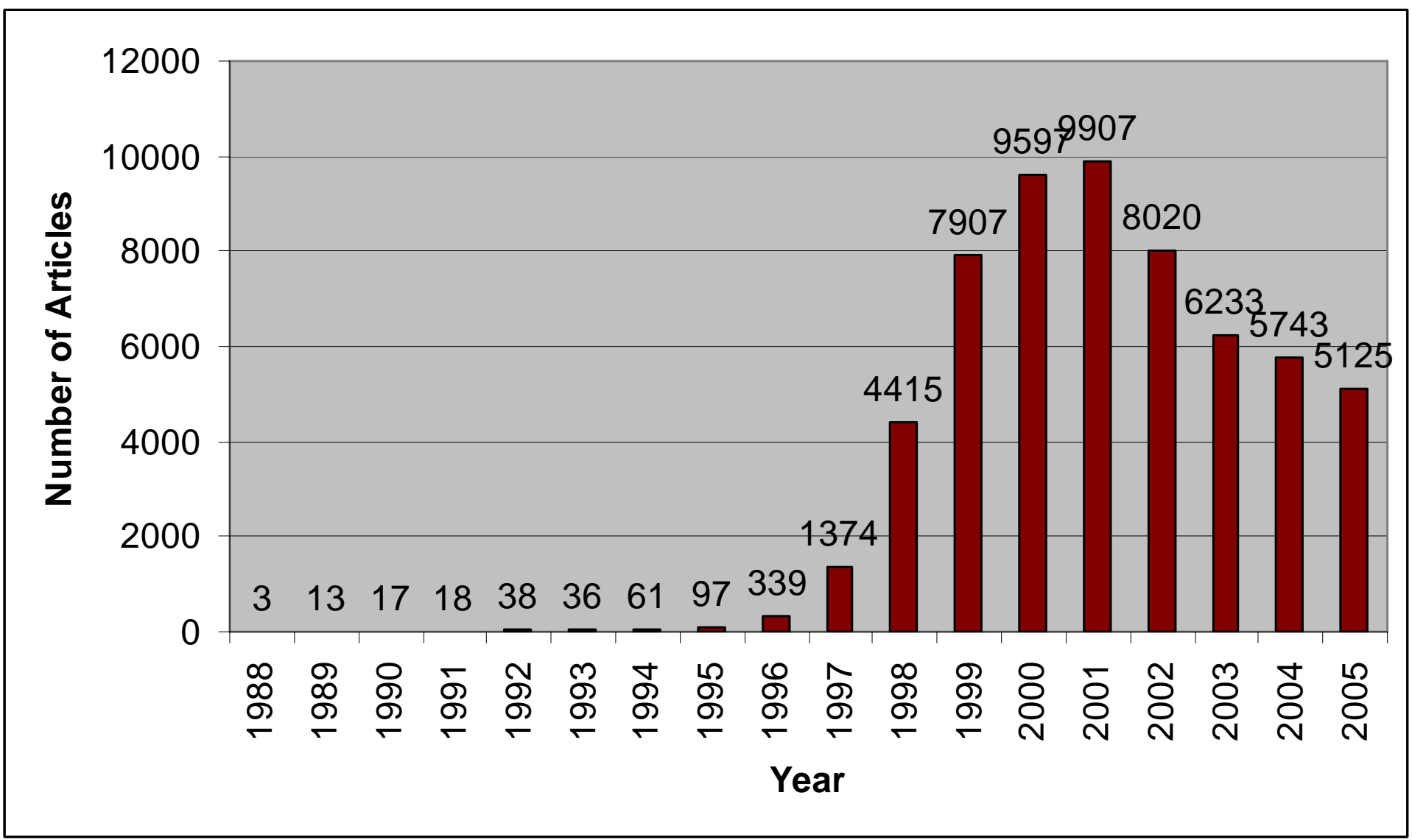

Figure 1: The number of Knowledge Management articles that appeared in Factiva Database

How about scholarly writing on KM? What perspective do these writings adopt in discussing case studies, and what type of evidence do they provide? These questions motivate the current study. Our goal is to compare the scholarly and professional literature in terms of type and quality of evidence provided in them. For this purpose, we have conducted a research of these two categories of writing (scholarly papers and popular books) in terms of the evidential support that they provide for their case studies. In the first category, we studied 26 papers published in six journals; in the second, we examined some of the most popular books on KM that are available to practitioners, and studied more than sixty different case studies reported in these books. Our key research questions throughout this study have been as follows:

- How much does the case examine the mundane aspects of KM and the related issues of trust, reward, incentives, and commitments of participants ([7])? 
- How much was IT central to the KM cases?

- What kinds of evidence for each case are presented to determine the success of the projects?

To conduct a systematic study, we generated a classification of the types of evidence presented in the literature (to be described later in the paper). Our original assumption was that the scholarly and professional literatures differ in terms of both the type and quality of evidence that they consider and present in their case studies. The outcome of the study, however, showed no considerable difference in terms of the types of evidence. Focusing our attention on the quality of evidence, however, we found interesting disparities between the two classes of literature, especially in terms of their attention to what we earlier called mundane aspects of KM. Although there is great variability within each category in this respect to warrant generalization - e.g., not all scholarly writings focus on mundane aspects, and not all practitioner books are managerialist - we have found sufficient disparity between the two categories to discern two versions of KM represented by each, which we call the "mundane" and "managerialistic" versions. We seek to explain the disparity between these two versions theoretically by drawing upon related work in science studies, especially actor-network theory (see [8] for detailed review on science and technology studies). The relation between theory and evidence is a central topic in the study of science (e.g., [9]), and different accounts of science provide various descriptions of this relation, often depending on the question(s) that they ask. We draw parallels between these accounts and the situation in KM in order to answer our research questions. We find significant differences between the two categories of literature in terms of the degree of "blackboxing" of evidence. This finding also suggests a prescriptive corollary - namely, that the health and future of KM research rests on the degree by which researchers engage in opening the blackbox of case-based evidence. KM scholars can contribute to this future depending on how much they manage to step out of the managerialistic framework into the realm of mundane KM.

The paper continues with a discussion of the theoretical background in philosophy and sociology of science (especially actor-network theory) and then with a discussion of our methods. We will then compare our preliminary findings with those of Schultze and Leidner [10] and introduce a typology of evidence, present our findings from the survey of the scholarly and popular KM literature on the basis of the above typology, and discuss these findings in terms of the ideas from actor-network theory. We conclude by using our findings to make sense of the current situation in KM and to draw lessons for its future.

\section{Lessons from Science Studies: Asking the Right Question}

In daily parlance, evidence is a broad term with a great deal of interpretational flexibility. Conventional wisdom takes as evidence a great variety of things, from physical objects or their traces to observation statements and reports: a smoking gun, a handkerchief, and a DNA trace could all count as evidence, as do a verbal testimony, a written will, and sometimes even hearsay. On the other hand, professionals such as detectives, lawyers, 


\section{The Quality of Evidence in Knowledge Management Research}

physicians, and intelligence workers who deal with evidence on a continuous basis, have developed more systematic and refined accounts of evidence that are specific to their institutional and cultural environment. In intelligence work, for example, a story or claim is ranged on a two-part measure (calibrated on the range of A through F), one being the credibility of the (intelligence) source, the other being the inherent plausibility of the story.

The notion of evidence also plays a central role in the realm of science, largely due to the interest on the part of scientists in demonstrating the objectivity of their findings and claims. Traditional empiricist accounts considered two senses of objectivity in science (e.g., [11], [12]). The first sense has to do with the truth and referential character of scientific theories, the second one with what is called the scientific method - i.e., with the way scientists obtain data and conduct experiments. The fundamental claim was that objectivity in the first sense derives from objectivity in the second sense. In other words, the objectivity of science was claimed to arise from the way scientists garner evidence in support of their theories. It was such that the notion of evidence acquired a central conceptual role in the twentieth-century philosophy of science. As Shapin ([13]) has shown, however, trust and gentlemanliness also played a central role in the validation and legitimation of early experimental science of the 17th century England, and there are lessons to be drawn from these practices as well.

During the last few decades, intensive debates and investigations around notions such as objectivity and evidence have resulted in radical changes in the understanding of notions such as evidence, objectivity, and truth In this paper, we briefly sketch these debates as they relate to our argument here. We believe that the information science community would greatly benefit from exposure to these debates.

Generally speaking, research into the character of scientific evidence can be motivated by different types of questions, such as:

- Does this piece of evidence confirm this hypothesis?

- Why do scientists take this piece of evidence to confirm this hypothesis?

- How do certain actors manage to convince others that what they present should be considered as evidence in support of a claim?

As we shall see, schools of thought differ partly depending on which question(s) they take to be central. Here we briefly discuss three major schools of thought which are, we believe, respectively motivated by the above three questions - namely, the positivist, contextualist, and actor-network views. As we shall see, these views are not necessarily mutually exclusive, and there might even be overlaps.

\subsection{The Positivist View of Evidence}

The traditional empiricist view of objectivity — that scientific theories are inductively confirmed by evidence obtained from direct observation — is problematic, mainly because many scientific theories appeal to entities and 
processes that are not observable (at least not in any straightforward sense of the term; cf. [9]). In mid-twentieth century, two major views grew out of this criticism. The first view is due to Karl Popper who believed, like David Hume (1711-76), that there is no justification for induction, and who introduced the notion of "falsification" in its place [12]. The second view is due to Carl Hempel, who shifted focus away from inductive justification and towards articulating the various criteria that scientists use in assessing theories. Popper's falsificationism, although more familiar to those outside the philosophy of science, does not interest us here, not only because of its inadequacies, but also because it does not have much to say about evidence. Hempel's positivist account, on the other hand, pays a lot of attention to the criteria used in theory assessment ([11]).

Hempel argued that the strength of support of a hypothesis by a given body of evidence depends on various characteristics of the evidence - most importantly, its quantity, precision, and diversity. The intuitions behind the first two criteria are almost obvious: the more evidence you have or the more precise your evidence is (whatever that means) the more support you have for your hypothesis. The criterion of diversity is trickier, however. Hempel explains it in the following way:

The more widely a set of experiments ranges over the diverse possibilities...the greater will be the chances of finding an unfavorable instance if [the hypothesis] should be false [11].

The argument for diversity seems to hold for some of the most established of scientific theories. Newton's theory of gravitation and of motion implies, for instance, the laws for free fall, for the simple pendulum, for the motion of the moon about the earth and of the planets about the sun, for the orbits of comets and of artificial satellites, for the motion of double stars about each other, for tidal phenomena, and many others. In other words, according to Hempel's argument, Newtonian mechanics is on solid grounds because it is supported by diverse evidence from so many areas. A scientific theory that applies to diverse situations and is supported by diverse evidence is therefore considered more viable in this view. Of course, some ways of increasing variety are considered pointless - e.g., an attempt to diversify the evidence in favor of Newton's laws by performing experiments in different places on earth, on different days of the week, or by experimenters of different eye colors or with different ages. Such diversification will not bring about more credibility for Newton's theories. Hempel is aware of this problem:

Thus, the qualification of certain ways of varying the evidence as important and of other ways as pointless is based on the background assumptions we entertain [11].

But he does not provide any clear solutions for it, except by mentioning that such background assumptions are perhaps a result of previous research. In other words, while paying attention to the role of background assumptions in selecting evidence, Hempel marginalizes this role as a minor issue and focuses on the question of evidential support that data lend to theories. 


\section{The Quality of Evidence in Knowledge Management Research}

\subsection{The Contextualist View of Evidence}

What seemed to be a minor issue for Hempel — namely, the role of background assumptions — turned into a central issue in later accounts of scientific knowledge. Helen Longino, for instance, gives a high priority to this issue. In presenting what she calls a “contextualist analysis of evidence,” Longino ([28]) argues that what a scientist counts as evidence for a theory depends, in the first place, on the other beliefs that the scientist holds. These background beliefs and assumptions, as they are usually called, are crucial in determining which hypotheses we accept as being confirmed by which evidence.

In order to illustrate her point, Longino uses the example of the parents who take the red spots on the stomach of their young child as evidence for measles. The interesting question, according to Longino, is why they take this as evidence for measles and not, for example, as evidence that the moon is blue. Longino explains this in terms of the background beliefs that the parents hold about the relation between the measles virus and the rash. Furthermore, she argues, the things that they regard as evidence can be described in a variety of ways.

An important aspect of Longino's account is that it takes physical objects, processes, and "states of affairs" as evidence. This is in sharp contrast to the positivist view, which focuses only on statements and logical relationships among them. The main focus of Longino's account is the second question outlined above - namely, why scientists take certain evidence, and not others, to support their hypothesis. Longino answers this question by invoking the background assumptions and beliefs of a scientific community, but she does not elaborate on how scientists achieve communal agreement - that is, how they manage to convince others of the plausibility of their claims.

\subsection{The Actor-Network View of Evidence}

Another school of thought focuses on this last question, seeking to understand the communal mechanisms that make it possible for certain actors to convince, align, and mobilize others behind their claims. Commonly known as the actor-network theory (ANT), this approach asks, How do actors translate a combination of data, observations, and ideas into "hardened facts" and "evidence" that is then blackboxed and handed down to others who take interest in it [15]? We believe that ANT provides a useful framework for discussing important issues of knowledge management. Let us therefore provide a synopsis of this approach and introduce three ANT concepts that we will use in this writing — namely, translation, reversible blackboxing, and performance.

Originating in science studies, actor-network theory is an evolving body of knowledge that is being applied to increasingly diverse fields of inquiry (see e.g., [16] for an analysis of the mediating role of information technologies in organizations). In rough outline, ANT analyses socio-technical processes in terms of networks where resources are concentrated in a few "nodes" connected with one another by links and the mesh [15]. A network, according to ANT, is comprised of human and nonhuman "actants" the most durable of which- 
people, institutions, tools, texts, money, technologies, information, etc. — flow through the network, in a way defining and creating the nodes. Depending on the relative flow and concentration of these "immutable mobiles," some nodes and actors may acquire a privileged status, rendering the situation "irreversible." That is, they find it possible to make autonomous choices that not only fall in line with those of the other actors but makes it impossible to go back to a point where alternative possibilities exist [17]. In order to create and populate networks, actors often employ different devices the common objective of which is to "translate" an idea, through the identification of a problem or opportunity, into reality [17].

One common device used in translation is "blackboxing" — an expression from the sociology of science that refers to "the way scientific and technical work is made invisible by its own success" [18]. "When a machine runs efficiently, when a matter of fact is settled, one need focus only on its inputs and outputs and not on its internal complexity. Thus, paradoxically, the more science and technology succeed, the more opaque and obscure they become” (ibid). One of the consequences of blackboxing is that by rendering technologies opaque and obscure, it tends to also obscure the paths that have led to specific technologies and the choices that were made on those paths. But this does not mean that the paths are irreversible. The notion of "reversible blackboxing" points to this fact - i.e., it captures the ever-changing, unstable character of associations made among different actants, which implies that at no point should they be taken for granted. Rather, continuous effort and intervention is required to maintain the links and associations.

This brings us to the ANT notions of intervention and "performance." These notions suggest a reality that is performed and enacted rather than simply observed - hence, giving rise to different "versions" of reality [19]. Although there is superficial similarity between the notion of performance and other "perspectival" or "constructionist" notions of reality, care should be taken not to confuse them with each other. An example might help. In her study of anaemia, Annemarie Mol discusses three performances or versions of this illness: i) the clinical version, which relies on a set of visible symptoms such as the color of eyelids; ii) the statistical version, which is based on the level of haemoglobin in the patient's blood and how it compares to other individuals in the population; and iii) the pathophysiological version, which depends on, for every single individual, the dividing line between the haemoglobin level that is enough to transport oxygen through the body properly, and the abnormal level which is too low [19]. As Mol argues, despite textbooks, in practice these versions do not always coincide in every given case, and may therefore lead to different diagnoses and treatments. And, as she emphasizes, it is important to notice that these are not different perspectives of different people, nor are they alternative bygone constructions of which only one has emerged from the past. They are "three different anaemias [that] have co-existed for decades now" [19] — they are different versions, different performances, and different realities.

We propose to apply the framework of ANT — particularly the three notions of translation, reversible blackboxing, and performance - to explain the situation of KM. We believe that there are different realities of $\mathrm{KM}$ out there, and the ones that are presented in scholarly and popular literatures, respectively, represent two 


\section{The Quality of Evidence in Knowledge Management Research}

versions of these. We call these the "managerial" and "mundane" versions of KM, and in the remainder of this writing we are going to introduce them by taking a close look at the picture that is provided in their respective writings. We argue that these versions of KM are two performances of the field.

If our argument about the existence of various versions of $\mathrm{KM}$ is correct, then it follows that there should be different sets of evidence garnered in support of each version. This means, in turn, that there is not much point in asking what evidence supports which version (as a positivist would ask), nor does it make sense to ask how people reach consensus (as the contextualist would have it), because there is none. Instead we believe that the situation in KM can be usefully understood by asking how certain actors (often consultants, gurus, and popular business writers) translate the data of certain cases into "evidence" that is then blackboxed and handed down to others who take interest in it. This is the question that we will try to elucidate in the remaining of this writing.

\section{Method}

As mentioned at the outset, our target in this study is the comparison of popular and scholarly literature on knowledge management. For this purpose, we looked at two groups of writing: i) popular books among practitioners, ii) scholarly journal papers. Let us briefly describe our method of locating the sources here.

To examine discourses in the popular literature, we examined well-accepted books in the public discourses of KM. In the examination of BPR as a "management fashion,” Benders and van Veen [20] selected the renowned book "Reengineering the Corporation: A Manifesto for Business Revolution” by Hammer and Champy [21] to demonstrate their argument. These popular books are much more reachable to the general public than academic journal articles. It is likely to find a book - e.g., Cultivating communities of practice [22] — than an academic journal - e.g., Management of Information Systems Quarterly — on a manager's desk. Hence we turned our attention to these books.

To determine the most popular books and to obtain a comprehensive picture, we collected lists of knowledge management books, such as Knowledge Management Book Bibliography [23], and coded each book by author's professions (e.g., consultant, scholar, journalist, etc.) and publisher (e.g., trade, academic, or hybrid, such as HBS Press). Although obtaining precise data about author affiliations is rather difficult, this preliminary analysis confirmed our assumption that most of these books are written by professional consultants or by academics who also have consulting jobs.

We then ranked the books by using Amazon.com's sales rank in January 2003 and April 2003. Although the ranks of some books changed during this period, the top twenty books were about the same. Among these, we selected five books from the top of the list, which provide cases of knowledge management used for our detailed analysis. These five books and their ranking are listed in Table 1. Each book includes a number of cases, usually 
presented as examples of successful KM implementation. We closely studied the cases, keeping in mind the research questions mentioned earlier, with an eye on the quality of evidence that they provide in support of their claims. In total, we analyzed 71 cases.

Similarly, for the scholarly writing on KM, we used six journals and analyzed 26 articles on the topic published between 1999 and 2004. These journals were examined by Schultze and Leidner [10] for a study of discourse analysis in KM. The six journals were: Accounting, Management, and Information Technologies; Information Systems Research; The Journal of Strategic Information Systems; European Journal of Information Systems; Journal of Management Information Systems, and MIS Quarterly. These articles were carefully studied for the evidence that they provide for their cases.

\begin{tabular}{|l|l|l|}
\hline Title & Author(s) & Amazon ranking $^{\mathbf{1}}$ \\
\hline Working Knowledge & Davenport \& Prusak (1998) & 2771 \\
\hline The Social Life of Information & Brown \& Duguid (2000) & 1985 \\
\hline Cultivating Communities of Practice & Wenger, McDermott, \& Snyder (2002) & 1338 \\
\hline $\begin{array}{l}\text { The Knowledge Evolution: Expanding } \\
\text { Organizational Intelligence }\end{array}$ & Allee (1997) & 15991 \\
\hline $\begin{array}{l}\text { The Knowing-Doing Gap: How Smart } \\
\text { Companies Turn Knowledge Into Action }\end{array}$ & Pfeffer \& Sutton (1999) & 10498 \\
\hline
\end{tabular}

Table 1. The five books used for this study, and the Amazon sales rank of each book.

In studying the cases, we coded them according to a typology of evidence that we have developed as follows.

\subsection{The Variety of Evidence}

In order to understand the nature of the evidence presented in the cases, we classified the evidence presented for them with the aim of generating a typology. We used a bottom-up method to develop the classification (see Table 2). Our proposed typology has five categories — outputs, outcomes, processes, culture, and perception. We note that the first four of these types are internal to the organization and the last one is external — that is, it refers to how the company is perceived in the outside world.

\footnotetext{
${ }^{1}$ The smaller the number is, the more number of the book has been sold.
} 


\begin{tabular}{|c|c|c|c|c|}
\hline \multicolumn{4}{|c|}{ Internal } & \multirow{2}{*}{$\begin{array}{c}\text { External } \\
\text { External perception }\end{array}$} \\
\hline $\begin{array}{l}\text { Quantitative } \\
\text { measures }\end{array}$ & Outcomes & Process & Human aspects & \\
\hline $\begin{array}{l}\text { - Productivity } \\
\text { - Financial reports } \\
\text { - Intellectual } \\
\text { capital } \\
\text { - Increasing } \\
\text { revenues } \\
\text { - Market share } \\
\text { - Use of system } \\
\text { - Efficiency }\end{array}$ & $\begin{array}{l}\text { - Innovation } \\
\text { competencies } \\
\text { - Standardized } \\
\text { methods }\end{array}$ & $\begin{array}{l}\text { - Awareness of } \\
\text { knowledge } \\
\text { creation } \\
\text { - Availability of } \\
\text { knowledge } \\
\text { - Strong social } \\
\text { network }\end{array}$ & $\begin{array}{l}\text { - Cultural issues } \\
\text { - Trust/ climate of } \\
\text { openness } \\
\text { - Participant } \\
\text { enthusiasm } \\
\text { - Build a shared } \\
\text { identity }\end{array}$ & $\begin{array}{l}\text { - Recognition } \\
\text { - Reputation } \\
\text { - Company’s customer } \\
\text { satisfaction }\end{array}$ \\
\hline
\end{tabular}

\section{Table 2. A Typology of Evidence}

The first category, outputs, is based on such evidence as productivity, financial reports, intellectual capital, increasing revenues, and market share. This type of evidence tends to rely on numbers and "hard" data.

The second category, outcomes, represents evidence having to do with innovations, competencies, and standardized methods. Standardized methods are often considered to promote consistent processes throughout an organization, and this in turn is supposed to facilitate knowledge sharing among the members of the organization. Therefore, many cases describe standardized methods as outcomes of their knowledge management strategy. For example, 3M's case [24] discusses new product innovation as a measurement of success for knowledge management initiatives.

The third category, processes, includes evidence such as awareness of knowledge creation, availability of knowledge, and strong social networks. Some cases (e.g., Chrysler's "Engineering Books of Knowledge" in [24]) explain that the development of databases that capture knowledge increases the availability of knowledge to the employees. In addition, some cases contend that the adoption of a knowledge management strategy increases employees' awareness of the knowledge created within their organizations or of other peoples' expertise. Therefore, one strong argument for a successful knowledge management strategy is to show stronger networks of people, which would make it possible for people to identify experts in certain areas and to ask the right questions from the right individuals.

The fourth category, culture, deals with issues such as trust, openness, participant enthusiasm, and building a shared identity. This category is, by its very nature, not very concrete. Cultural issues are indicators of the 
degree of willingness within an organization to share knowledge. Orlikowski's work [25] found that consultants were not inclined to share their knowledge because the culture of the consulting firm was very competitive and they did not wish to loose their competitive advantage. Ekbia and Hara [26] have discussed the kinds of issues and challenges that KM projects face in implementing incentive structures for knowledge sharing. Similar issues emerge in regards to trust and openness. Hara, Solomon, Kim, and Sonnenwald [27] describe how a group of scientists were unwilling to share their knowledge without having a strong sense of trust among each other. Participant enthusiasm usually refers to the comments made by employees who take part in knowledge management projects, with positive comments typically considered a measure of success of the project. Another indicator of a successful knowledge management strategy is the building of a shared identity. This measurement is discussed often in conjunction with building communities of practice (c.f., [22]).

In addition to the above four categories of internal evidence, there is also an external category, which has mostly to do with the outside perception and recognition of the company - e.g., having a reputation for implementing a successful knowledge management strategy, being featured in a magazine, or getting high satisfaction rates from the organization's customers.

\section{Findings}

Based on the typology of evidence presented above, we analyzed the cases both quantitatively and qualitatively. Quantitatively, we counted the number of studies that refer to each type of evidence in their reports and discussions. Tables 3 and 4 show the number of cases that mention each type of evidence and the pertinent percentage of each type in the professional and scholarly literature, respectively. 


\begin{tabular}{|c|c|c|c|c|}
\hline \multicolumn{4}{|c|}{ Internal } & \multirow{2}{*}{$\frac{\text { External }}{\text { External perception }}$} \\
\hline $\begin{array}{c}\text { Quantitative } \\
\text { measures }\end{array}$ & Outcomes & Process & Human aspects & \\
\hline $\begin{aligned} & \text { - } \text { Productivity (12) } \\
& \text { - } \text { Financial reports } \\
&(1) \\
& \text { - } \text { Intellectual } \\
& \text { capital (15) } \\
& \text { - } \text { Increasing } \\
& \text { revenues (13) } \\
& \text { - Market share (2) } \\
& \text { - Use of system } \\
& \text { (12) } \\
& \text { - Efficiency (17) }\end{aligned}$ & \begin{tabular}{|l} 
- Innovation \\
competencies \\
$(24)$ \\
- Standardized \\
methods (31)
\end{tabular} & \begin{tabular}{|l} 
- Awareness of \\
knowledge \\
creation (44) \\
Availability of \\
knowledge (44) \\
- Strong social \\
network (26)
\end{tabular} & \begin{tabular}{|l} 
- Cultural issues (27) \\
- Trust/ climate of \\
openness (27) \\
- Participant enthusiasm \\
(18) \\
- Build a shared identity \\
$(22)$
\end{tabular} & $\begin{array}{l}\text { - Recognition (3) } \\
\text { - Reputation (5) } \\
\text { • Company's customer } \\
\text { satisfaction (3) }\end{array}$ \\
\hline $72(20.7 \%)$ & 55 (15.9\%) & 115 (33.1\%) & $94(27.1 \%)$ & $11(3.2 \%)$ \\
\hline
\end{tabular}

Table 3. Typology of Evidence in the Professional Literature

\begin{tabular}{|c|c|c|c|c|}
\hline $\begin{array}{c}\text { Quantitative } \\
\text { measures }\end{array}$ & Outcomes & Process & Human aspects & External perception \\
\hline $\begin{array}{l}\text { - } \text { Productivity (1) } \\
\text { - Financial reports } \\
\text { (1) } \\
\text { - Intellectual } \\
\text { capital (1) } \\
\text { - Increasing } \\
\text { revenues (4) } \\
\text { - Market share (-) } \\
\text { - Use of system (1) } \\
\text { - Efficiency (3) }\end{array}$ & $\begin{array}{l}\text { - Innovation } \\
\text { competencies } \\
\text { (7) } \\
\text { - Standardized } \\
\text { methods (11) }\end{array}$ & $\begin{array}{l}\text { Awareness of } \\
\text { knowledge } \\
\text { creation (12) } \\
\text { Availability of } \\
\text { knowledge (13) } \\
\text { Strong social } \\
\text { network (7) }\end{array}$ & \begin{tabular}{|l} 
- Cultural issues (3) \\
- Trust/ climate of \\
openness (-) \\
- Participant enthusiasm \\
(4) \\
- Build a shared identity \\
(2)
\end{tabular} & $\begin{array}{l}\text { - Recognition (2) } \\
\text { - Reputation (1) } \\
\text { - Company’s customer } \\
\text { satisfaction (2) }\end{array}$ \\
\hline $11(14.7 .0 \%)$ & $18(24.0 \%)$ & $32(42.7 \%)$ & 9 (12.0\%) & $5(6.7 \%)$ \\
\hline
\end{tabular}

Table 4. A Typology of Evidence in the Scholarly Literature 
A number of points follow immediately from the tables. First, they show that there is indeed a variety of evidence presented in both literatures. Second, they indicate a strong emphasis on processes (33\% of evidence) and culture (27\% of evidence), accounting for a total of $60 \%$ of the evidence provided for the cases. This reflects a shift from the earlier technocentric view toward a more human-centric view of computerization (in this case, of KM systems). Last, and most important for our purposes, the professional and scholarly literature do not seem to significantly differ from each other in terms of the types of evidence that they provide. This point, as we said, stands contrary to our initial expectation, and it can be explained in one of two ways. One is to say that there is indeed no difference between the two literatures, and hence between the perspectives that they adopt. The other explanation would be to assume that there is a difference but that our typology does not capture it. The second explanation would only hold if one goes deeper into the case studies, looking behind the numbers and percentages of types of evidence and finding other differences in perspective and approach. We decided to follow this tack.

For this purpose, we took a close look at some of the case studies reported in the two literatures, and we believe that we did find differences. To demonstrate the further analysis, we will discuss in more detail one case from each category that, we believe, is representative of the approach in each. One case is the Virtual Team Program at British Petroleum, which is discussed in various books such Working Knowledge by Thomas Davenport and Larry Prusak [24] and The Knowing-Doing Gap by Pfeffer and Sutton [1]. The other case comes from a paper by Elisabeth Davenport [4]. Being aware that two single cases may not genuinely represent two categories of literature, we do not intend to venture into unwarranted generalizations here. Through our study, we are convinced that these cases are also roughly representative of the two literatures, and we shall provide explanations in the Discussion section of why this is the case. However, whether and how much they are representative is not central to our goal, which is to highlight the differences in perspective (managerial versus mundane) that these cases demonstrate.

\subsection{Case I: British Petroleum}

In the introductions to their book, Davenport and Prusak, making the widely-accepted distinction between data, information, and knowledge, provide the following "pragmatic descriptions” of knowledge in organizations:

Knowledge is a fluid mix of framed experience, values, contextual information, and expert insight that provides a framework for evaluating and incorporating new experiences and information. It originates and is applied in the minds of knowers. In organizations, it often becomes embedded not only in documents or repositories but also in organizational routines, processes, practices, and norms [24]. 


\section{The Quality of Evidence in Knowledge Management Research}

On this basis, the authors declare as the primary aim of their book the development of a preliminary understanding of what knowledge is within organizations, as captured in the following questions:

How does it look and sound in daily life and work? How is it different from data and information? Who has it? Where is it? Who uses it? What do we talk about when we talk about knowledge? [24].

As a secondary concern of the book, however, the authors mention the pragmatic issue of "what to do with knowledge,” as captured in the following questions:

What key cultural and behavioral issues must we address to make use of it? What are the best ways to use technology in knowledge work? What are specific knowledge roles and skills? What does a successful knowledge project look like and how do you know if it has been successful? What measures and milestones can we use to evaluate it? [24].

These are all interesting questions which could provide, in the authors' own words, a response to the essential question: What do I do Monday morning to help make our organization's use of knowledge more effective? However, of special interest to us are the last two questions about the evaluation of KM projects. Given the authors' explicit attention to these questions, one would hope to find useful answers to them in the context of the case studies presented throughout the book. A close look at the cases, however, reveals an obvious downplaying of these issues. Indeed, all the criteria and measures are based on the claims made by high-ranking managers of the companies, without a critical evaluation of the claims.

One such example is British Petroleum (BP)’s Virtual Teamwork Program — a pilot project, whose proclaimed goal was to enhance communication within and across company offices around the globe. To illustrate the success of this project, Davenport and Prusak report two episodes: In the first episode, drilling engineers use a video camera to televise via satellite - a faulty component for an expert who diagnoses and solves the problem by guiding the engineers through the repair process. According to the authors, this prevented a shutdown that would have necessitated flying an expert or sending the ship to the port — a saving of hundreds of thousands of dollars, according to the report. In the second episode, one of the teams is reported to take advantage of the applicationsharing feature of the virtual-team clients to write joint memos in just ten minutes - a process that would have otherwise taken hours and days. The authors summarize their evaluation of this project as follows:

The success of virtual teamworking in four of the five groups that took part in the pilot was demonstrated by the volume of use, participant enthusiasm, and measurable savings in time and money [italics added]. Tellingly, the single failure occurred in the Petrochemical group, whose members were mainly interested in exchanging data, not knowledge; the VT clients' potential for delivering richly varied communication did not interest them. In addition, that was the one group that, for budgetary reasons, did not have the benefit of coaching. [24]

These examples, undeveloped and unsupported, illustrate the typical casualness with which professional consultants handle evidence. They point to the large gap that exists between reported episodes and the authors' conclusions - i.e., "the volume of use, participant enthusiasm, and measurable savings in time and money." In particular, we notice that: 
- There is no interesting relation between the reported episodes and knowledge management (as defined by the authors themselves); rather the reports simply illustrate the advantages of, respectively, modern satellite communication and run-of-the-mill client-server architectures;

- There is no discussion of the costs incurred by these projects in terms of equipment (video, satellite, computers, etc.) in comparison to the savings;

- The only case of reported failure is simply attributed to an interest in "data" rather than "knowledge" with no elaboration on what that means;

- It is not clear which participants, how, and why were enthusiastic about the project.

In short, there is a systematic lack of evidence for the claims put forth about the alleged success stories, and the minor evidence that is provided usually comes from managers and heads of IT who are the initiators and benefactors of the projects. A similar approach is noticed in almost all the other cases reported in Working Knowledge - e.g., Daimler-Chrysler, Hewlett-Packard, IBM.

Interestingly, many of these cases are also invoked as successful examples of KM in the other popular books listed in Table 1. The other books might vary in terms of the specifics of arguments, but they provide, by and large, a similar quality of evidence. Pfeffer and Sutton [1], for instance, also discuss the BP case, quoting verbatim from Davenport and Prusak's report of the drilling platform mentioned above, and supporting these claims by interviews with top-ranking BP executives. We observe a similar pattern of enthusiastic and optimistic accounts of KM cases in other popular writings. The cases tend to conceal which actors (e.g., consulting firms) are involved and what the outcomes of these projects are, and only a small portion of them are supported by research and empirical fieldwork and examined through a critical perspective.

\subsection{Case II: Virtual Tourism Enterprises}

In her paper, Mundane Knowledge Management and Microlevel Organizational Learning: An Ethological Approach, Elisabeth Davenport [4] starts with a notion of knowledge that would deal with the "detailed local routine and repair activity that underlies the smooth functioning of an organization.” Building on Suchman's writings (e.g., [28]) on "articulation work," Davenport presents a conception of knowledge management that takes seriously the local management of "mundane" knowledge. She develops this concept by means of a case study of an organizational learning initiative intended to promote the formation of virtual enterprises.

In this initiative, a team of researchers is assigned the task of developing KM packages for tourism SMEs (small and medium enterprises) in order to make them competitive with larger companies. The consortium proposes the establishing of "virtual enterprises" that would organize them into alliances using the technologies and techniques of e-commerce. For this purpose, the team adopts a communities of practice perspective, keeping the following questions in mind [4]: 


\section{The Quality of Evidence in Knowledge Management Research}

- How is the knowledge to get work done presented and appropriated in online enterprise?

- How may structured interaction contribute to the management of daily practice in on-line groups?

- Can persistent practices for mundane knowledge management emerge in problem-based or scenario-based learning settings?

Davenport describes in detail the development of the project in five phases, the hurdles that were faced, the changes that needed to be made, and the lessons that were drawn in this process. Among the lessons, she highlights the issues of "trust," "a sense of presence," "a sense of solidarity among learners," the importance of "backchannels" and "spaces in the learning platform for private dealings," and so on [4]. At the same time, she emphasizes the role of mundane knowledge managers who "take over at times of breakdown," and of "the physical environment of the users (the technology)" as well.

This brief summary illustrates a rather different view of knowledge management from that of practitioner literatures. The two views start with different questions and, of course, arrive at different answers. However, as we discuss next, they also seem to be motivated by different goals, having separate allies and audiences in mind.

\section{Discussion}

Our study of professional and scholarly KM literatures reveals two version of knowledge management, which seem to differ not only in their understanding of the concept of "knowledge" and in what constitutes organizational knowledge, but also in how they think about effective knowledge sharing mechanisms and their implementations. This difference can be usefully explained from the perspective of actor-network theory in terms of two networks of actants (people, technologies, texts, etc.) connected together through a set of common interests and ideas. The human actors in these networks - consultants, top executives, managers, information officers, and trade publishers, in one case; academic researchers, IT professionals, employees, and scholarly journals, in the other- enter the situation with different motivations and interests, and might have different understandings, stakes, and commitments in the related projects. In short, these actants achieve various performances, creating two different versions of knowledge management. One is the professional consultant version of $\mathrm{KM}$, best represented in a number of popular books that can be found on the desks and bookshelves of many of the other actors in the pertinent network. The cases provided in these books are often based on a number of "success" stories that are blackboxed and passed along to other consultants, executives, managers, etc. who take interest in them. The other is the scholarly version, represented by the research and writings of some academics who tend to view knowledge management from a non-managerial perspective. These writings also circulate within their own network, picked up by other scholars who are interested in the same topic, and disputed or developed further. 
These two networks obviously interact and even overlap with each other: there are academics who do consulting, for instance, sometimes competing with professional consultants in the same market. But there is sufficient separation and adequate autonomy to make the two networks distinct from each other. One major source of distinction, we argue, is in the degree of blackboxing involved in each network, with the professional literature ranking higher in this respect. In business, as in science, blackboxing tends to cover the paths that have led to the final outcome, the choices that were made along the way, the options that were abandoned, the costs that were incurred, and so on. What makes blackboxing more stark in the professional literature, however, is the alleged success of the cases reported in it. Professional consultants are typically paid by executives to evaluate their business performance, including their KM systems. And more often than not, they are predisposed to give more weight to the goals and concerns of those same executives. For example, "participant enthusiasm," which is included under "human aspects" in Table 2, does not necessarily represent participant/employee's perspective. How much participant enthusiasm for a knowledge management strategy could one count on when it is reported in a marketing brochure? How could one discern between a voice that is actually coming from the participant, pretended enthusiasm due to management pressure, or marketing and public-relation tropes? Similar observations can be made about many of the other entries in Table 2 - e.g., "the availability of knowledge" (under the process category) and "the climate of openness" (under human aspects).

The point of these questions is not to raise skepticism about the honesty and candor of managers and professionals whose statements constitute the bulk of evidence reported in the popular KM literature. The purpose is to provide a balanced and clear account of the inner mechanisms, hidden costs, untried paths, and available options. This is the spirit of the "critical" perspective advocated in social informatics, and represented in the works of, among others, Rob Kling. Kling and his colleagues developed a framework called "sociotechnical interaction networks" (STIN), which is very close to ANT in its major premises and methods [29]. One important aspect of this perspective is that it does not automatically consider technologies as value- free entities, but it critically examines how technologies are used in organizations and it particularly pays attention to issues such as trust, reward, incentive, and commitment. This perspective is typified in Davenport's paper discussed above. In our view, this approach avoids the vacillations that often take place in professional IT literature between techno-centric and human-centric views. Our study shows that, in examining KM and computerization in organizations in general, the following questions are important to ask:

- Which actors are involved?

- Whose version of KM is being considered?

- Which actors need to be convinced in order for a project to succeed? Which ones should be isolated?

- What are the mobilization strategies of different actors?

- What stage in the process are they in? 


\section{The Quality of Evidence in Knowledge Management Research}

\section{Conclusion}

The evaluation of computer systems in organizations has been a central issue of IS research in the past couple of decades, and much has been learned from studies that focus on this issue ([30], [31], and all the subsequent literature built upon it is a prominent example). We believe that the issue of system evaluation cannot be separated from the discourses about systems, and the "versions" that are generated by such discourses. The issue of evidential support, then, becomes central only in this light. The main challenge, we believe, is to ask the right question in regards to evidence. We have noticed that the diversity of evidence, advocated by the positivist view, does not necessarily confirm a claim, especially if all the evidence emanates from a specific stance. We have also noted that asking about the background assumptions, as proposed by the contextualist view, is not sufficient because different groups might have different sets of assumptions, which give rise to different "versions" of KM. In this paper, we conducted a comparative study of two such versions, and suggested that asking the kinds of question posed from a critical social-informatics perspective can provide useful insights into the issues of evidential support in KM research.

One consequence of a noncritical perspective, as far as the assessment of evidence is concerned, is to put the burden of proof on the wrong side. In jurisdiction, where evidence is central to the process, the burden of proof usually falls on the side of the party who makes a claim about someone or something. This does not seem to be the case in KM research and literature, where the burden of proof usually falls on the side that disputes claims on knowledge management as a magic bullet [32]. During 1990s, a majority of researchers and practitioners leaned toward the notion that knowledge management can be a panacea for all business and organizational problems. Following the economic turnaround, however, this view was adjusted. Small wonder that we observe a pattern of declining interest in KM in different places. Similar trends were found in previous IT interventions, such as BPR [33] and Groupware, as well as in management strategies such as Learning Organization and Total Quality Management. There has been tremendous effort on the part of IS community to explain this state of affairs. One group of theories rely on the notion of "hype cycle" originally developed in [34]. Researchers who study KM have also applied this notion to explain patterns of the kind we see in Figure 1.

Accounts such as "hype cycle" are helpful, especially when they are verified empirically, but they fall into what philosophers of science call descriptive accounts. These are accounts that restrict themselves to the phenomenology of events — i.e., they are mostly interested in "what-questions," not in "how-questions." In the topic under discussion, for instance, these accounts ask, What is the hype cycle of knowledge management [35]? As we said, the answers that such descriptive accounts arrive at often provide useful insights, but they are limited by the kind of the question that they ask. For example, they do not ask how the hype cycles are created. Actornetwork theory, on the other hand, provides a useful conceptual framework for addressing this kind of question. The notions of translation, blackboxing, and performance used in this paper provide helpful conceptual tools for understanding the mechanisms that are at work in the promotion of ideas such as KM. We believe that ANT 
notions can also provide answers to the broader question of how hype cycles are generated. The notion of "reversible blackboxing" that we mentioned earlier, for instance, captures the unstable character of the associations made among different actors - a phenomenon that seems to prevail in repeated management hype cycles; the notion of performance portrays the situation as one of multiple realities of KM, not just one.

There is also a normative corollary to all of this. It turns out that the example of scholarly work discussed here is dominant in academic research on KM. Schultze and Leidner [10], in a study of works published in the Management of Information Systems (MIS) journals (during the tens years preceding their study), found that the majority (70\%) of research on KM was done from an "elite" (researcher and manager) perspective and only 28\% was found to emanate from a local (i.e., workers) perspective [35]. This indicates a great deal of overlap in this respect between what we have called managerial and mundane knowledge management, suggesting that scholarly research into KM can establish its separate identity by focusing on the mundane aspects of KM.

\section{Acknowledgements}

The idea of this work was originated by the late Rob Kling, and the authors would like to dedicate it to his curious, critical, and caring spirit. May this contribute to the continuance of that spirit in IS research. The authors would also like to thank Blaise Cronin for helpful comments and graduate students Xuan Ma and Eric Hinchman for their efforts in conducting the analysis of the literature.

\section{References}

[1] J. Pfeffer and R.I. Sutton, The knowing-doing gap: How smart companies turn knowledge into action, (Harvard Business School Press, Boston, 2000).

[2] P.M. Hirsch and D.Z. Levin, Umbrella advocates versus validity police: A life-. cycle model, Organization Science, 10(2) (1999) 199-212.

[3] P.H. Gray and D.B. Meister, Introduction: fragmentation and integration in knowledge management research, Information Technology \& People, 16 (3) (2003) 259-265

[4] E. Davenport, Mundane Knowledge Management and Microlevel Organizational Learning: An Ethological Approach. Journal of American Society for Information Science \& Technology, 53(12) (2002) 1038-1046.

[5] L.J. Ponzi and M. Koenig, Knowledge management: Another management fad? (2002) Information Research, 8(1). Available at: http://informationr.net/ir/8-1/paper145.html (accessed 26 July 2004). 
The Quality of Evidence in Knowledge Management Research

[6] Z. Guo and Sheffiled, A paradigmatic and methodological examination of KM research: 2000-2004, Available at: http://doi.ieeecomputersociety.org/10.1109/HICSS.2006.23 (accessed 8 September 2006).

[7] R. Kling, A Critical Professional Education about Information and Communication Technologies and Social Life. Information Technology and People, 16(4) (2003), 394-418.

[8] N. Van House, Science and technology studies and information studies, Annual Review of Information Science and Technology, 38 (2004) 1-86

[9] M. Curd and J.A. Cover. Philosophy of science, The central issues. (1998, W.W. Norton \& Co., New York).

[10] U. Schultze and D.E. Leidner, Studying knowledge management in information systems research: Discourses and theoretical assumptions. MIS Quarterly, 26(3) (2002) 213-242.

[11] C.G. Hempel, Philosophy of natural science, (Prentice Hall, Englewood Cliffs, 1966).

[12] K. Popper, The logic of scientific discovery, (Basic Books, New York, 1959).

[13] S. Shapin, A social history of truth: Civility and science in seventeenth-century England, (The University of Chicago Press, Chicago, 1994).

[14] H. Longino, Science as social knowledge: Values and objectivity in scientific inquiry. (Princeton University Press, Princeton, 1990).

[15] B. Latour, Science in Action, (Harvard University Press, Cambridge, 1987).

[16] H.R. Ekbia, How IT Mediates Organizations: Enron and California Energy Crisis, Journal of Digital Information, 5(4) (2005). Available from http://jodi.ecs.soton.ac.uk/Articles/v05/i04/Ekbia/

[17] M. Callon, Techno-economic Networks and Irreversibility. In J. Law (Ed.), A Sociology of Monsters (Routledge, London, 1992).

[18] B. Latour, Pandora's hope: Essays on the reality of science studies, (Harvard University Press, Cambridge, 1999).

[19] A. Mol, Ontological politics: A word and some questions. In: J. Law and J. Hassard (eds.), Actor Network Theory and after (Blackwell/The Sociological Review, Oxford/Malden, 1999).

[20] J. Benders and K. van Veen, What's in a fashion? Interpretative viability and management fashions. Organization 8(1) (2001) 33-53.

[21] M. Hammer and J. Champy, Reengineering the corporation: A manifesto for business revolution. (HarperCollins, New York, 1993).

[22] E. Wenger, R. McDermott and W.M. Snyder, Cultivating communities of practice: A guide to managing knowledge. (Harvard Business School Press, Boston, 2002). 
[23] P.W. Rosen, Knowledge Management book bibliography (2002). Available at: http://www.kmadvantage.com/km_bibliography.htm (accessed 27 November 2003).

[24] T.H. Davenport and L. Prusak, Working knowledge: How organizations manage what they know. (Harvard Business School Press, Boston, 1998).

[25] W.J.Orlikowski, Learning from Notes: Organizational issues in groupware implementation. The Information Society, 9 (1993) 237-250.

[26] H.R. Ekbia and N. Hara, Incentive Structures in Knowledge Management. In: D.G. Schwartz (ed.), Encyclopedia of Knowledge Management, (Idea Group, Hershey, 2005).

[27] N. Hara, P. Solomon, S. Kim, and D.H. Sonnenwald, An Emerging View of Scientific Collaboration: Scientists' Perspectives on Collaboration and Factors that Impact Collaboration. Journal of American Society for Information Science \& Technology, 54(10) (2003) 952-965.

[28] L. Suchman, Making a case: 'knowledge' and 'routine' work in document production. In: P. Luff, J. Hindmarsh and C. Heath (eds.) Workplace studies: Recovering work practice and informing system design, (Cambridge University Press, Cambridge, 2000).

[29] R. Kling and S. Iacono, Computerization movements: The rise of the Internet and distant forms of work. In: J. A. Yates and J. V. Maanen (eds.), Information Technology and organizational transformation: History, rhetoric and practice, (Sage Publications, Thousand Oaks, 2001).

[30] W. H. DeLone and E.R. McLean, Information systems success: the quest for the dependent variable, Information Systems Research, 3(1) (1992) 60-95.

[31] W.H. DeLone and E.R. McLean, The DeLone and McLean Model of Information Systems success: A tenyear update, Journal of Management Information Systems, 19(4) (2003) 9-30.

[32] M.L. Markus and R.I. Benjamin, The Magic bullet theory in IT-enabled transformation, Sloan Management Review, 38(2) (1997) 55-68.

[33] V. Allee, The Knowledge Evolution: Expanding Organizational Intelligence (Butterworth-Heinemann, Newton, 1997).

[34] F. Caldwell, D. Miklovic, and D. Morello, Hype Cycle of Knowledge Management. Available at: http://www.edocument.org.sa/Hype_Cycle.pdf (Accessed 22 December 2003)

[35] N. Hara and R. Kling, Professional development \& knowledge management via virtual spaces. In: J. Weiss, J. Nolan, P. Trifonas (eds.), International Handbook of Virtual Learning Environments, (Kluwer Academic Publishers, Dodrecht, 2006).

[36] J.S. Brown and P. Duguid, The Social Life of Information (Harvard Business School Press, Boston, 2000). 